\title{
RELAÇÕES SÓCIO-ESPACIAIS ENTRE NATIVOS E VERANISTAS NO LITORAL SUL DE SERGIPE
}

\author{
RELATIONSHIP SOCIO-SPACE BETWEEN NATIVES AND \\ SUIMMERINGS IN THE SOUTH COAST OF SERGIPE
}

\section{RELACIONNES SOCIO- ESPACIALES ENTRE LOS NATIVOS Y VERANISTAS EN EL LITORAL SUR DE SERGIPE}

\author{
Roseane Cristina Santos Gomes \\ Mestre em Desenvolvimento e Meio Ambiente/UFS \\ Docente do curso de Geografia da Universidade Federal de Sergipe/UFS, \\ Campus de São Cristóvão/SE \\ Endereço Postal: Rua Alagoas, 2000, \\ Residencial Costa Norte B1.10, AP. 204, Bairro José C. de Araújo. \\ CEP: 49085-050. Aracaju-SE \\ E-mail: roseane.ufs@gmail.com
}

Maria Augusta Mundim Vargas

Doutora em Geografia; Professora Colaboradora do Núcleo de Pós Graduação em Geografia NPGEO/UFS e do Programa de Pós Graduação em Desenvolvimento e Meio Ambiente PRODEMA/UFS

Endereço Postal: Rua Euclides Góes, 263, Bairro Coroa do Meio. CEP: 49035310. Aracaju-SE E-mail: amundim@infonet.com.br

\section{Resumo}

Os povoados Porto do Mato e Saco do Rio Real, localizados no município de Estância/SE, são palco de transformações sócio-espaciais balizadas por um processo crescente de especulação imobiliária ligado ao turismo de veraneio. Essas transformações, por seu turno, podem não estar contribuindo com as comunidades, principalmente no tocante a melhoria das condições socioeconômicas da população local, ou na conservação dos aspectos naturais. Portanto, a análise feita neste artigo, gira em torno das relações sócio-espaciais que se estabelecem entre sujeitos nativos e não nativos (veranistas) nos povoados já explicitados. Para tanto, foram utilizados como procedimentos observação direta, constituída de registros fotográficos e conversas informais; entrevistas com roteiro pré-estruturado e, por um vasto levantamento documental sobre o processo de ocupação dos povoados. Isto posto, consideramos que a forma de ocupação que está sendo desencadeada necessita de uma atuação planejada por parte do Poder Público, nas suas diversas esferas. Caso isso não ocorra, este segmento 
espacial provavelmente sofrerá impactos ambientais gravíssimos, não desconsiderando os já ocorridos.

Palavras-Chave: Território, Multiterritorialidade, Turismo, Veraneio, Litoral Sul de Sergipe

\begin{abstract}
The Porto do Mato and Saco do Rio Real towns belongs at Estância/SE city, are stage of social-space transformations marked out by an increasing process of real estate speculation due to the summering and too much tourist activities. These transformations, for its turn, can not be contributing with the communities, mainly in regards to improvement of the socioeconomics conditions of the local population, or in the conservation of the natural aspects. Therefore, the analysis done in this article turns around the partner-space relations that were establish between native and not native citizens (summering) in the mentioned towns already. For that, we had been used as procedures direct comment, consisting of photographic registers and informal colloquies; interviews with script daily pay-structuralized and, for a vast documentary survey on the process of occupation of the towns. This rank, we consider that the occupation form that is being unchained needs from an action planned by the government in its diverse spheres. In case this does not occur, this space segments, probably will suffer serious environmental impacts, not disrespecting the already occurred ones.
\end{abstract}

KeyWords: Territory, Multiterritoriality , Tourism, Summering, South coast of Sergipe.

\title{
Resumen
}

Las veredas Porto do Mato y Saco do Rio Real, situados en el municipio de Estância/SE, son palco de transformaciones socio- espaciales impulsado por un creciente proceso de especulación de las propiedades inmobiliarias encendido por el turismo del verano. Estos cambios, a su vez, no puede estar contribuyendo a las comunidades, especialmente en relación con la mejora de las condiciones socioeconómicas de la población local, o en la conservación de los aspectos naturales. Por lo tanto, el análisis hecho en este artículo, gira alrededor de las relaciones socio espacilales que se establecen entre nativos y no nativos en las veredas explicitadas ya. Para ello, los procedimientos que se han utilizado fueron la observación directa, que consiste en los registros fotográficos y conversaciones informales, entrevistas estructuradas con pre-escritura, y un amplio estudio documental sobre el proceso de ocupación de las veredas. Dicho esto, creemos que la forma de ocupación que se desencadeno necesita de una acción planeada por el gobierno en sus diversas esferas. Si no es así, el segmento espacial probablemente sufrira graves impactos ambientales, sin tener en cuenta los que ya se producen.

Palabras - Clave: Território, Multiterritorialidad, turismo, verano, costa sur de Sergipe 


\section{Introdução}

A temática envolvendo padrões de racionalidade de exploração da natureza e a ocupação do espaço pode nos oferecer a oportunidade de estudarmos um dos aspectos da organização social, suscitando leituras sobre como uma sociedade concebe suas relações, tendo em vista os elementos que a estruturam e que se manifestam na configuração do ambiente físico e sociocultural.

A análise aqui explicitada gira em torno das relações sócio-espaciais que se processam entre sujeitos sociais que fazem parte da dinâmica dos povoados Porto do Mato e Saco do Rio Real, localizados no município de Estância, litoral sul do Estado de Sergipe que, atualmente, passou por um processo de ocupação desordenada, impulsionado pelo turismo que se manifesta principalmente, através do veraneio.

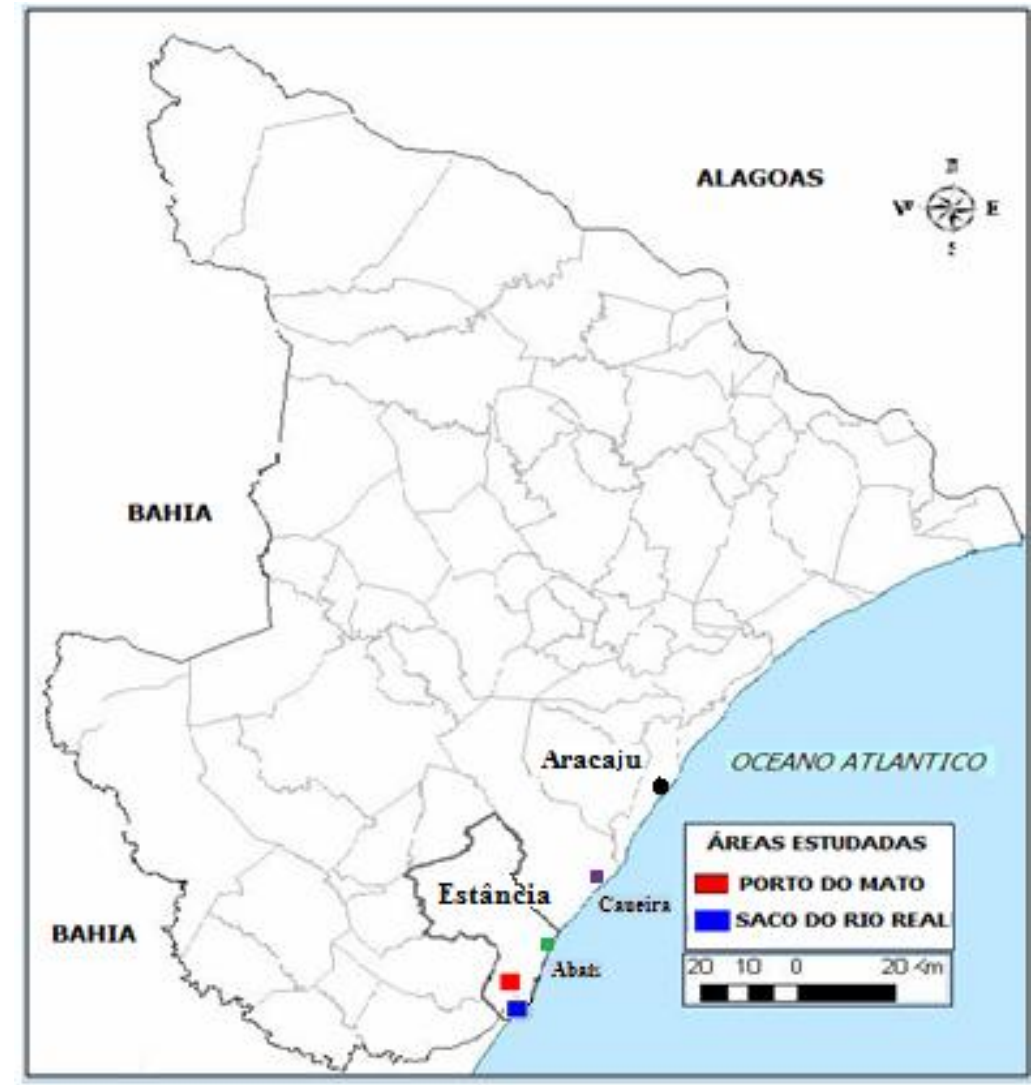

Figura 01: Localização da área de estudo

Fonte: modificado a partir do Atlas digital sobre Recursos Hídricos do Estado de Sergipe. SEPLAN, 2004. 
A pesquisa, realizada entre 2007 e 2009, foi estruturada pela observação direta, constituída de registros fotográficos e conversas informais; pela compilação de entrevistas com roteiro pré-estruturado e por um vasto levantamento documental sobre o processo de ocupação dos povoados. No tocante a entrevista, a amostra foi definida pelo conteúdo oferecido pelos entrevistados, ou seja, até o conteúdo das respostas sobre o lugar se repetir de forma considerável. Entrevistamos veranistas que efetivamente contribuíram para mudanças nas formas de uso e ocupação do solo nas localidades em questão e os nativos mais antigos, os filhos destes com mais de vinte anos de idade, além dos migrantes de retorno que estão nas localidades desde a década de 1980. Ao todo foram feitas vinte e sete entrevistas, sendo vinte com os nativos e sete com os veranistas.Com esses procedimentos foi possível identificar as formas diferenciadas de ocupação das residências de veraneio, desvelando-nos o contraste entre as residências dos nativos e dos não-nativos, aqui nomeados veranistas.

A ocupação do litoral sul sergipano foi iniciada pelos franceses que, no século XVI adentraram o complexo estuarino formado pelos rios Real, Piauí e Fundo e instalaram feitorias às margens do rio Piauí, dando origem à atual cidade de Santa Luzia do Intanhy. No lado oposto de suas águas, bem próximo do mar, situa-se o povoado Saco do Rio Real e, adentrando no estuário, às margens do rio Real e Fundo, encontrase o povoado Porto do Mato. Todavia, a chegada dos portugueses e a conseqüente expulsão dos franceses em 1575 se deram com a tomada de Santa Luzia do Intanhy, com a fixação de novo ponto de colonização no Mangue Seco, margem baiana do estuário do Rio Real e, com a penetração de colonos nos vales férteis dos rios Piauí e Real, dando origem à cidade de Estância no século XVII, mas também deslocando o desenvolvimento desta para o interior ${ }^{1}$.

Já em meados do século XVIII, o município de Estância se constituiu em próspera província, devido a sua posição geográfica privilegiada, sendo banhado pelo Oceano Atlântico e pelo rio Piauí, que lhe proporcionaram excelente porto, passando a ser a rota de convergência de todas as exportações do Estado de Sergipe, que segundo Wanderley (1998) ficou caracterizado como detentor das vias de acesso marítimofluvial mais praticáveis de todo o Estado.

\footnotetext{
${ }^{1}$ A esse respeito, ver DINIZ (1999); SOUZA et al (1995); WANDERLEY (1998).
} 
Assim, apesar do processo de formação territorial deste município ter se iniciado no litoral, o seu desenvolvimento se fez de fato, mais para o interior, devido ao cultivo da cana -de -açúcar nos solos mais apropriados e sua importância para a economia da coroa Portuguesa. Nesse contexto, os sito dos povoados Porto do Mato e Saco do Rio Real não se prestaram às instalações portuárias e, portanto, subsistiram à margem da dinâmica econômica até o segundo quartel do século $\mathrm{XX}$, quando o isolamento geográfico foi rompido com a construção da estrada de acesso a estes segmentos espaciais na década de 1970.

As comunidades desses povoados se reproduziram de forma endógena, com a pesca e cultivos de subsistência e, a questão que se coloca advém do processo de transformação espacial evidenciado pelas novas formas de uso do solo, através da dinâmica impressa pelos condomínios, loteamentos e pelos novos sujeitos do lugar.

\section{Turismo de Segunda Residência ligado ao Veraneio}

O fato de o espaço ser o principal objeto de consumo do turismo, este transforma alguns territórios para o seu uso, ao mesmo tempo em que valoriza espaços que poderiam não ter valor no contexto da lógica da produção (CRUZ, 2002). A valorização deste se dá através das relações sociais e da influência do marketing.

Nesse sentido, o turismo é uma atividade complexa e multifacetada tendo seus reflexos nas diferentes esferas sócio-espaciais. $\mathrm{Na}$ econômica, requalifica os espaços através da diversificação do crescimento ou decréscimo das atividades, provocando alterações no perfil dos empregos, da renda e da produtividade; na cultural, pelo fato de modificar os sistemas de valores, os estilos de vida e o padrão de consumo das populações receptoras; na ideológica porque articula estratégias e táticas que permeiam o imaginário do turismo como forma de salvação do mundo e como mecanismo de manutenção da ordem; na política - (re) define o papel do Estado como gerenciador da infra-estrutura do turismo e da ordem; na espacial, refere-se ao espaço como meio de produção, como produto do consumo e como lócus das práticas sócio-espaciais.

O turismo analisado no viés geográfico engloba nesse estudo, a dinâmica sócioespacial mediante a abordagem dos processos que engendram a atividade turística. As práticas sociais influenciam a mobilidade, circulação de idéias, novos conhecimentos e distanciamento do ambiente cotidiano, tudo o que motiva e condiciona o turismo. $\mathrm{O}$ 
olhar geográfico sempre busca entender o espaço através das relações que a sociedade estabelece com a natureza, suas relações socioeconômicas e culturais, pois segundo Carlos:

O turismo cria uma idéia de reconhecimento do lugar, mas não o seu conhecimento, reconhecem-se imagens antes veiculadas, mas não se estabelece uma relação com o lugar, não se descobre o seu significado pois os passos são guiados por rotas, ruas preestabelecidas por roteiros de compras, gastronômicos, históricos, virando um ponto de passagem. (CARLOS, 1996, p. 31).

De acordo com Coriolano e Vasconcelos (2007) o turismo no Brasil começa a surgir oficialmente em 1964, com a publicação de um guia turístico elaborado pelo Ministério da Indústria e Comércio, e 1966 com a criação do Conselho Nacional do Turismo e a Empresa Brasileira de Turismo (Embratur). A partir desse momento, houve um crescimento e diversificação das modalidades turísticas realizadas no país, com a participação de organismos oficiais e empresas particulares.

Em nível de Nordeste, o PRODETUR-NE (Programa de Desenvolvimento do Turismo) é a política pública de maior expressão, a partir do final do século XX (entre os anos de 1980-1990), sendo o alvo maior as cidades litorâneas, alicerçadas por políticas públicas de valorização das zonas de praia transformadas em pontos de recepção e de distribuição do fluxo turístico. De acordo com Dantas,

\footnotetext{
O volume de investimentos aplicados aponta o turismo litorâneo como um dos principais vetores econômicos na região Nordeste, a exigir adoção de políticas econômicas desenvolvimentistas que culminaram no fortalecimento de racionalidade de organização do espaço díspare na região nordeste de outrora (Dantas, 2009, p. 48)
}

Já na área de estudo o turismo que se manifesta é aquele ligado a residência secundária de veraneio. Segundo Tulik (2001), residências secundárias são consideradas domicílios particulares que servem de moradia ou de estada turística, excluindo os hotéis, relacionados à recreação e ao lazer do usuário. São utilizadas durante o fim de semana, férias ou outro fim, diferençando-as da residência permanente, também denominada principal, normal ou primária, ou seja, o ocupante deste tipo de residência, deve obrigatoriamente habitar outro domicílio, considerado principal. 
Porém, foi a partir do século XVIII que a zona litorânea passou a ser alvo desse tipo de turismo, sendo então introduzido o veraneio no mundo ocidental, pois até então essa porção do espaço era repudiada pela elite ocidental. O mar, a partir de então, passa a ser visto como lugar de encontro com a natureza até para tratamento terapêutico. De acordo com Linhares (1992), a prática do veraneio que é considerado como um movimento de valorização do litoral pela elite iniciou-se como explosão inicial na Europa e, posteriormente, na América do Sul: no Chile, no Uruguai e Brasil.

No caso do litoral nordestino brasileiro a valorização destes espaços se estabelece denotando transformações no seio da sociedade urbana cuja essência não se constitui em suporte da vida cotidiana (SEABRA, 1979).

De acordo com Castro (2006, p.6), os turistas internacionais das grandes metrópoles e da terceira idade estão transformando a residência secundária de veraneio na nova atração do mercado imobiliário, sendo os maiores negócios realizados em Natal e Salvador

Em Sergipe, a presença da residência secundária se faz em toda a faixa litorânea, embora com padrões de ocupação distintos, o que vai depender principalmente do poder aquisitivo de quem se insere nesse contexto.

Já na porção litorânea do município de Estância/SE, entre as formas de usoocupação mais perceptíveis está a atividade turística que se manifesta associada à estruturação urbana de povoados que começam a apresentar equipamentos turísticos, ora aparecendo articulada a espaços de residência secundária, que mobiliza proprietários de terras, incorporadores, corretores e a indústria de construção civil; e ora aparecendo como indutora da ocupação de novas áreas com vistas à expansão da rede hoteleira, embora ainda incipiente, porém promissora.

Os povoados Porto do Mato e Saco do Rio Real experimentam um processo de reordenamento do uso do espaço e do tempo, tendo em vista a convivência com o turismo, em especial o veraneio em sua dimensão sazonal.

Um fator importante que influencia na dinâmica do espaço turístico e na localização das residências secundárias é a rede de acesso e transporte. Apesar de estas se localizarem, geralmente, ao redor das áreas urbanas mais adensadas, elas podem se espraiar por distâncias maiores, devido às qualidades dos meios e vias de transportes disponíveis, bem como do poder aquisitivo do interessado. 
O município de Estância está inserido no Pólo Costa dos Coqueirais classificado pelo Programa de Desenvolvimento do Turismo - PRODETUR-NORDESTE como potencialmente turístico e mais contemplado com projetos de desenvolvimento do turismo, entre os quais destacamos a construção da Orla do povoado Abaís e das rodovias que fazem parte do Projeto Linha Verde, ligando Bahia a Sergipe, estas beneficiando a área de estudo.

Essas transformações influenciaram no interesse das classes sociais mais abastecidas, sobretudo da capital Aracaju, pelas praias do litoral sul como lugar privilegiado para a construção de suas residências secundárias. Assim, os espaços litorâneos passam a assumir novas características sociais, demográficas e urbanísticas, marcados pelo deslocamento da população e pela mudança dos usos, resultantes das presenças dos veranistas e outros tipos de turistas sazonais (URBAIN, 1996 apud DANTAS 2006, p. 272).

A questão acima levantada pode causar repercussões negativas a exemplo das mais corriqueiras que se referem ao fato de as residências secundárias, geralmente, “desalojarem com suas edificações e infra-estruturas o uso do solo tradicional anterior, agrícola e pesqueiro e provocarem turbulência em níveis culturais e sociais (perfil de empregos, alteração dos estilos de vida, entre outros) e ambientais (desorganização da drenagem e mudanças geomorfológicas, destruição das qualidades das águas doces e oceânicas)" (BARROS, 1998, p. 28). Tal realidade não está distante daquela encontrada nos povoados Porto do Mato e Saco do Rio Real.

Por outro lado, a residência secundária propicia aos seus proprietários o reencontro com a natureza, sem que estes abdiquem do conforto compatível com o seu nível de vida alcançado.

Segundo Moraes:

O litoral também se particulariza, modernamente, por uma apropriação cultural que o identifica como um espaço de lazer, por excelência, e os espaços preservados são, hoje, ainda mais valorizados nesse sentido. Isto sustenta uma das indústrias litorâneas de maior dinamismo na atualidade, qual seja a que serve às atividades turísticas e de veraneio (MORAES, 1999, p. 18).

O processo de incorporação da zona de praia enquanto objeto de consumo no município de Estância teve início na área de estudo nos anos 1970, sendo os primeiros 
ocupantes (visitantes) originários do próprio município; porém tal processo intensificouse nos anos 1980 pela melhoria do acesso. Os povoados Porto do Mato e Saco do Rio Real passaram a ser ocupados com maior intensidade por volta de 1990, em sua maior parte (em especial o segundo povoado) por famílias de classes média, média alta e alta, que "fugiram" do crescimento do fluxo de pessoas nas praias do Abaís e Caueira que, pela proximidade de Aracaju, foram as primeiras a serem ocupadas. Dessa forma, fica nítido o movimento continuo que marca o interesse dessas classes pelo "descobrimento" e ocupação de lugares "selvagens", rústicos, isolados, pouco adensados (GOMES, R. C. S, 2007).

De acordo com observações feitas e depoimentos dos entrevistados, atualmente os povoados Porto do Mato e Saco do Rio Real apresentam cerca de 500 residências secundárias de veraneio. A prefeitura municipal de Estância não possui o registro exato da quantidade dessas residências. Tal afirmação foi comprovada através de visita aos órgãos que teoricamente seriam responsáveis por questões ligadas ao planejamento territorial do município.

Em visita feita à prefeitura municipal de Estância e Secretarias Municipais de Planejamento e Finanças, além de informações prestadas pelos responsáveis por estes órgãos, nota-se que a prefeitura não dispõe de um número exato dos loteamentos e casas de veraneio nos povoados em questão. Esse fato evidencia a carência de planejamento territorial deste segmento litorâneo e o consequente despreparo da Prefeitura Municipal de Estância. Nesse contexto se inclui também a falta de preocupação com as comunidades que estão inseridas nessas localidades cujas propriedades servem de atrativo imobiliário dentro da lógica do turismo em suas diversas formas. Neste sentido, Yázigi (2001) alerta que diferentes lugares turísticos de todo o mundo estão ficando "com a mesma cara", esteticamente estandardizados, uma vez que a arquitetura implantada negligencia a "identidade paisagística" dos lugares. 


\section{Compartimentação do Território}

O turismo age (des) territorializando e produzindo novas configurações geográficas. Assim, é que os espaços litorâneos, originalmente ocupados pelos pescadores, comunidades tradicionais, os chamados "povos do mar", são expropriados para dar lugar às residências secundárias, aos grandes resorts, às cadeias hoteleiras, aos restaurantes e demais equipamentos turísticos. Nessa produção espacial, se faz necessário considerar a luta dos diferentes sujeitos locais: os nativos, usuários do espaço litorâneo que tentam defender suas propriedades, ou bens de usos, ou muitas vezes tentam se adequar às relações que são estabelecidas e impostas pelo turismo. Nesse jogo de interesses, cabe aos empresários, aos especuladores imobiliários, aos proprietários de residências secundárias e ao próprio Estado, vislumbrar estes espaços de potencial turístico como valor de troca, pois o transformaram em mercadoria.

$\mathrm{Na}$ área de estudo em questão, o crescimento do veraneio levou a uma distinção espacial: de um lado o espaço de recreação, presentes em ambos os povoados; de outro lado, espremida nos cantos, e freqüentemente em reduzidos quarteirões, as casas dos nativos, os remanescentes do mundo natural transformado, situação essa bem evidente no povoado Saco do Rio Real. Já os nativos do povoado Porto do Mato que, apesar de contar com uma população composta por mais de 1500 habitantes, têm suas atividades tradicionais desvirtualizas, a exemplo da pesca, pelo turismo de veraneio. O que seria uma fonte de sobrevivência transformou-se em produto de comercialização a serviço dos visitantes sazonais.

As mudanças causadas pelo turismo de veraneio são preocupantes, não somente sobre o ambiente físico, mas sobre as formas tradicionais de vida. As dificuldades em se manterem as atividades tradicionais, como a agricultura e a pesca, associadas à melhoria dos meios de comunicação, aceleraram o êxodo de grande parte dos nativos do Saco do Rio Real, submetendo estes à venda de suas propriedades e a introdução de outras atividades associadas ao turismo.

A partir da decadência das atividades tradicionais, alguns dos seus habitantes não têm muitas alternativas econômicas, e muitos passam a viver da renda conseguida durante três ou quatro meses do ano, em atividades ligadas ao turismo.

Estudos realizados por Wanderley (1998) e Gomes (2006 e 2007) sinalizam que ambas as comunidades aqui explicitadas podem estar ameaçadas em sua sobrevivência 
física e material, considerando tratar-se de comunidades que até a década de 80 eram consideradas totalmente tradicionais. Esta afirmação pauta-se principalmente em relatos dos sujeitos sociais locais dentro de estudos realizados pelas autoras citadas. Essa ameaça ocorre por vários fatores e processos que estão ligados pela carência de planejamento que regule as novas formas de uso e ocupação do solo ligado ao avanço da especulação imobiliária iniciado na década de 1980 e 1990. Neste estudo, Planejamento é uma ferramenta de gestão que, para Almeida (2005) constitui em um rigoroso processo de dar racionalidade à ação, onde se deve enfrentar de forma criativa, as situações que se apresentam. Desta forma o planejamento e gestão devem deve assumir espaço vital nas formas de uso e ocupação do solo, da praia do Saco, buscando dentro deste processo a autogestão, a autonomia e a sustentabilidade dessas populações na perspectiva da conservação dos recursos naturais e do patrimônio material e imaterial dos povos costeiros.

Ainda segundo Almeida (2005) os danos causados pelo turismo invasivo e pela construção de casas de veraneio sem planejamento podem ser irreversíveis, minando por completo, a identidade cultural do povo receptor.

Esta nova forma de ocupação do espaço privou parte dos nativos de suas posses na praia, induzindo a novas relações dentro desse processo de (re) configuração do lugar. Hoje, têm-se diaristas, pesca para comércio, prestação de serviço de várias formas.

Outro aspecto é a mobilidade, pois muitos nativos saíram de seu lugar, base da sua identidade para tentar melhores condições de vida em outras localidades, passando assim por um processo de (re) territorialização. Este aspecto é bem evidente no povoado Saco do Rio Real. 


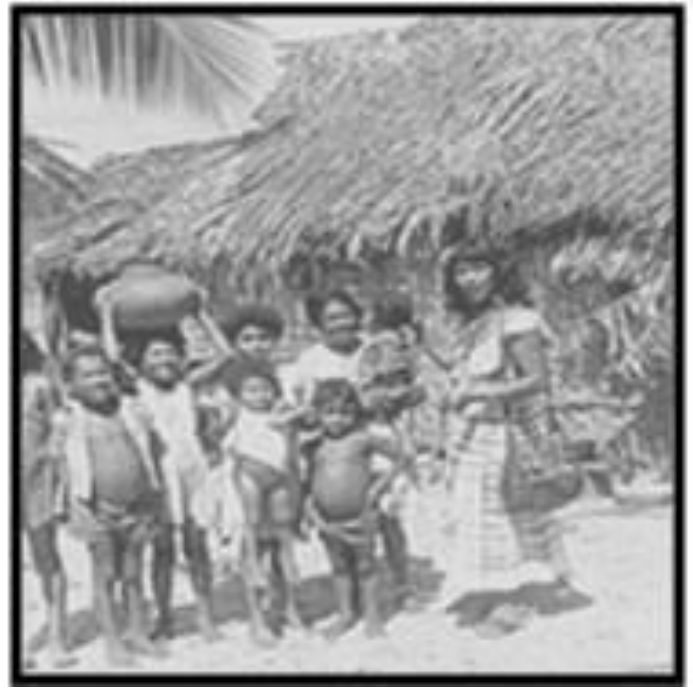

Figura 02: família nativa do povoado Porto do Mato - década de 1970. Fonte: LEEB (1996, p.58).

A população deste povoado sofreu um processo de êxodo que se iniciou no final da década de 1970 e se dá até os dias atuais. Muitos venderam seus terrenos a preços módicos para pessoas interessadas em construir suas segundas residências.

"A maioria das pessoas da região foram embora. Acabou assim, o povo do lugar. Hoje têm pouquíssimo. Venderam seus terrenos. Hoje em dia querem voltar pra aqui e não conseguem. Vendiam baratinho. $\mathrm{O}$ veraneio modificou a paisagem né.[...]. Eu achava melhor como era antes", (Raimunda - nativa do Povoado Saco do Rio Real)

Os povoados Porto do Mato e Saco do Rio Real, apesar de próximos, diferenciam-se na forma como os veranistas se apropria de cada uma dessas localidades: a construção das residências secundárias de veraneio nos dois povoados se deu com a melhoria de acesso com a construção da rodovia Ayrton Senna, principal via de acesso ao litoral estanciano. Porém, a proximidade do mar transformou o Saco do Rio Real em atrativo maior para pessoas com alto poder aquisitivo. O padrão e tamanho das residências são evidentemente superiores que aquelas localizadas no Porto do Mato.

Portanto, quanto à distribuição espacial, o veraneio é mais concentrado no povoado Saco do Rio Real, até mesmo porque este segmento espacial está localizado à beira mar. Foram identificados vários loteamentos que evidenciam o uso do espaço para fins de lazer turístico, com registros na Secretaria de Finanças da Prefeitura Municipal de Estância. 
Estes loteamentos, em sua maioria, localizados do povoado Saco do Rio Real, são ocupados por construção de residência de veraneio. Atualmente, uma das fortes características dessa localidade é o predomínio de casas dos mais variados padrões, em detrimento da pequena presença dos moradores nativos que se expressam em números consideravelmente menores.

As residências nativas estão localizadas predominantemente, nas margens da principal via de acesso à praia do Saco. Poucas estão distribuídos no interior do povoado.

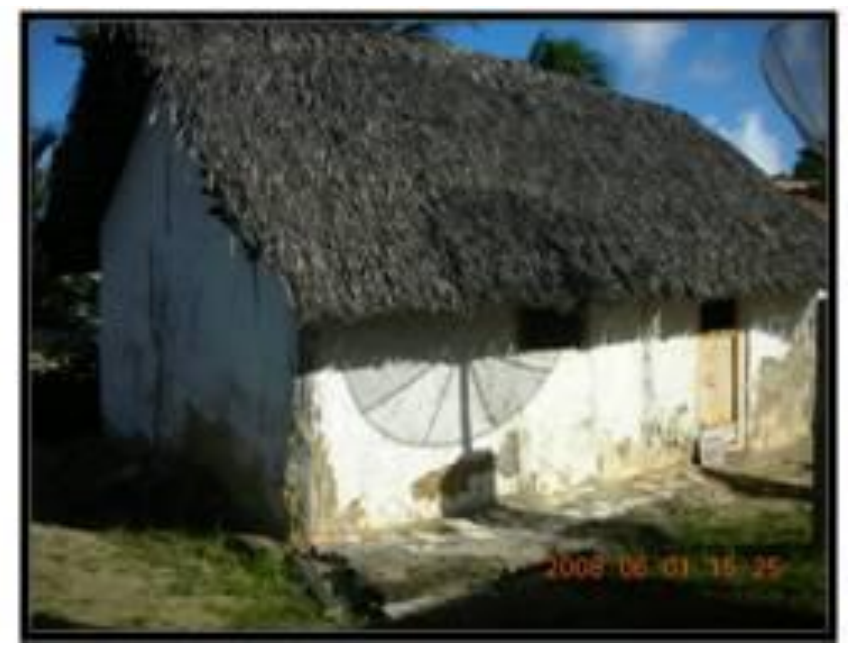

Figura 03: padrão de residência dos nativos - povoado Saco do Rio Real Fonte: Gomes R. C. S., pesquisa de campo, 2008.

A priori, quando se chega ao povoado Saco do Rio Real, não é perceptível o predomínio do veraneio sobre a comunidade local. Apenas quando se vai adentrando nas estradas que em sua maioria não possuem pavimentação é que se vai dando conta de que o povoado está perdendo os seus nativos, pois a quantidade de residências de veraneio é muito grande.

As residências secundárias estão presentes por todo o povoado e ao seu redor, sendo que aquelas localizadas no seio da comunidade são de características mais simples, aparentando pertencer aos veranistas com um moderado poder aquisitivo, se comparadas às residências que ocupam a porção periférica do povoado. $\mathrm{O}$ isolamento desses veranistas foi notório, e as residências sazonais se assemelham às mansões, dentro de um espaço onde habita uma população marcada pelas desigualdades socioeconômicas. 
É tão marcante a discrepância da paisagem construída que é possível ter a impressão de que não existe uma população marginalizada e carente de cuidados por parte do Poder Público em suas variadas esferas.

Já o povoado Porto do Mato encontra-se mais afastado do mar. O processo de ocupação por parte dos veranistas deu-se após o processo ter se iniciado no Saco do Rio Real.

As características dessa forma ocupação do solo neste povoado são totalmente distintas da explicitada no povoado anterior: foram observadas poucas residências de veraneio.

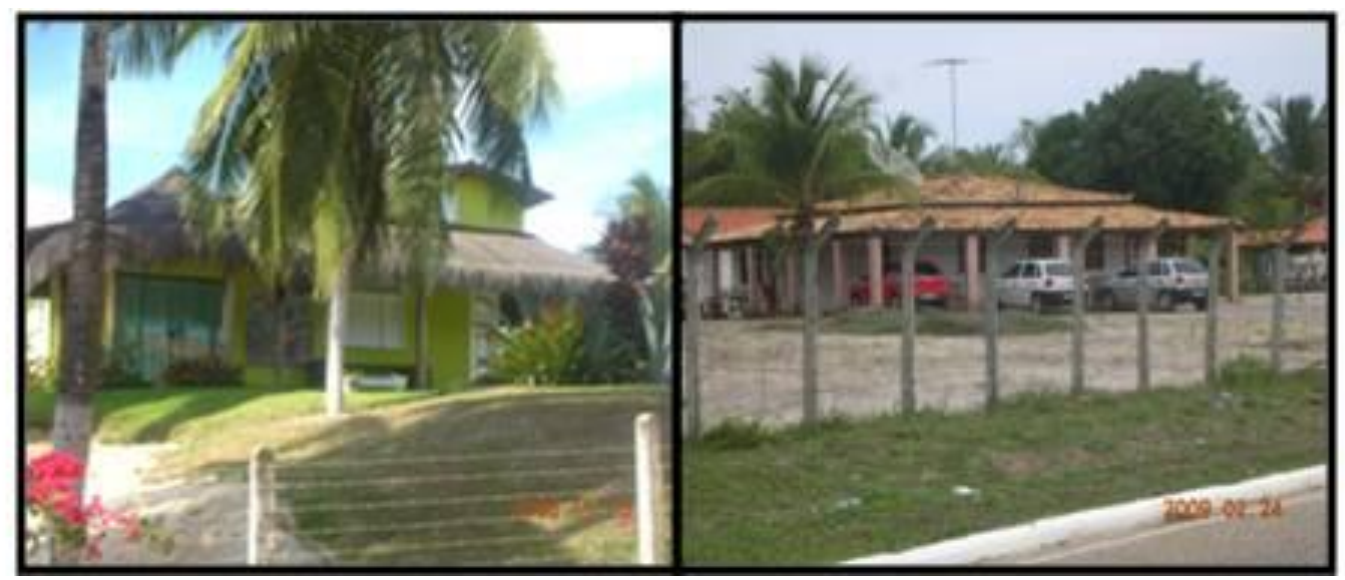

Figura 03: padrão de residência de veraneio no povoado Saco do Rio Real e Porto do Mato, respectivamente

Fonte: Gomes R. C. S., pesquisa de campo, 2008 e 2009.

O padrão das casas não é luxuoso. São casas simples pertencentes a famílias que, em geral advêm do interior do Estado de Sergipe, como Lagarto, Simão dias, entre outros. Há o predomínio da população nativa. Estas residências estão distribuídas ao longo das margens da rodovia Airton Sena, não sendo muito frequente encontrá-las no interior do povoado.

\section{Multiterritorialidade: Quem é Quem Nesse Pedaço?}

No jogo contemporâneo dos processos de descrição e reconstrução territorial, fica muito claro o ir e o vir entre territórios mais impregnados de um sentido funcional, de controle físico de processos (ou mais estritamente, no caso em que a dimensão simbólica - a territorialidade, para alguns) adquire um papel fundamental. 
Nessa vertente, Haesbaert (2007) propõe o território dentro da perspectiva de um contínuum que se estende da apropriação mais especificamente simbólica até a dominação funcional no sentido mais estrito. Daí o sentido da multiterritorialidade, que caminha no viés da mobilidade crescente e a complexidade das relações na atualidade, levando à construção da territorialidade, que é também mais móvel e de caráter múltiplo.

Foi observado na área de estudo um preocupante processo de migração realizado pelos nativos, sendo que o ponto de partida é o seu lugar de origem, onde outrora mantinham relações básicas de família, parentesco e outros. Mas, com o fluxo do movimento migratório, por causa da territorialização do capital cultural, econômico e político e dos conflitos daí advindos, forjam os deslocamentos em escalas espaciais diferenciadas. Becker (1997), em seu estudo sobre mobilidade espacial da população, afirma:

Os deslocamentos de populações em contextos variados e densevolvendo ao longo do tempo escalas espaciais diferenciadas conferiam complexibilidade crescente ao conceito de mobilidade como expressão de organizações sociais, situações conjunturais e relações de trabalho particulares. A cada nova ordem mundial correspondeu uma nova ordem econômica com a emergência de novos fluxos demográficos. (BECKER, 1997:319)

Nesse sentido, a memória que carregam de outros lugares entra em conflito quando chegam ao lugar definitivo e vislumbram a possibilidade de construírem, por meio de suas representações de mundo, suas práticas sociais e estratégias de luta. As relações sócio-espaciais que passam a se concretizar no lugar não são mais de estrangeiros, mas fruto de uma trajetória de conquistas em que a história desses sujeitos sociais, vivenciadas no cotidiano da nova sociabilidade que se apresenta, propõe a reconstrução e utopias estabelecendo um novo sentido de pertencimento. Muitos nativos foram tentar melhores condições de vida na sede municipal, no município de Aracaju e outros municípios do Estado de Sergipe e até fora dele.

Outro aspecto observado nesses espaços turístico receptores foi a ocorrência de diferentes tipos de territorialidades que se confrontam entre si: territorialidades dos que vivem frequentemente nestes espaços e a territorialidade dos que apenas passam por eles ou seja, indivíduos que trazem consigo a segregação sócio-espacial, a diferentes formas de acesso à terra e os problemas ambientais, o que caracteriza o processo de 
territorialização e desterritorialização na dinâmica das relações estabelecidas entre nativos e não nativos, os veranistas. Estes, muitas vezes estão alienados dos impactos ocasionados pela aquisição de lotes nessas áreas litorâneas.

A segregação do espaço com diferenciações no nível de qualidade de vida em relação aos antigos moradores é um reflexo de um cotidiano urbano construído no século XX e intensificado no século atual com a globalização, que traz consigo a segregação sócio-espacial, a diferentes formas de acesso à terra e os problemas ambientais, o que caracteriza o processo de produção do espaço.

Daí a relação sócio-espacial, estabelecida entre os que são filhos do lugar e os não nativos, estarem sob o prisma de uma nova dinâmica, principalmente no povoado Saco do Rio Real. Este processo está consolidado, com o predomínio de casas de veraneio dos mais variados padrões, dos mais simples aos mais sofisticados (mansões), em meio a uma comunidade que está se diluindo, desaparecendo, migrando em busca de melhores condições de vida.

É conveniente afirmar que todo espaço é de alguém, é o espaço do mais forte, de uma cultura dominante, em que um grupo se sobressai sobre outro, controla os meios de vida, terra, capital, matérias primas, força de trabalho, tentando fazer da sua verdade a realidade de cada um através do senso comum, impondo sua própria experiência do mundo. Então, o ser do e no mundo encontra-se imerso em um espaço que nem sempre atende aos seus interesses, atende a interesses de poucos.

Assim, devemos primeiramente distinguir os territórios de acordo com os sujeitos que os constroem, sejam eles indivíduos, grupos sociais, o Estado, empresas, instituições como a Igreja etc. As razões do controle social pelo espaço variam conforme a sociedade ou cultura, o grupo e, muitas vezes, com o próprio indivíduo. Para Rafestin (1983), controla-se uma 'área geográfica', ou seja, o 'território', visando 'atingir/afetar', influenciar ou controlar pessoas, fenômenos e relacionamentos.

O espaço, no qual a área de estudo está inserida é, portanto, cada vez mais disputado, não sendo mais possível simplesmente ocupá-lo ou explorá-lo. É necessário, geri-lo, isto é, conceber de forma integrada as ações que ali se desenvolvem.

Ao longo desta abordagem foi percebido que a forma de ocupação que está sendo desencadeada necessita de uma atuação planejada por parte do Poder Público, tanto na esfera municipal, quanto da estadual. Caso isso não ocorra, este segmento 
espacial provavelmente sofrerá impactos ambientais gravíssimos, não desconsiderando os já ocorridos.

\section{Considerações Finais}

As transformações em andamento não estão dissociadas das categorias de análise tempo e espaço que consideram este último enquanto local de reprodução das relações sociais, e onde o tempo se materializa. São transformações que se justificam ou pela necessidade de integrar as sociedades rurais nos mercados regional, nacional e internacional na expectativa de melhorar a sua condição socioeconômica, ou pela própria necessidade de sobrevivência. Os povoados aqui em evidência trazem cada vez mais no seu conteúdo a essência das novas dinâmicas sócio-espaciais, que têm no turismo um dos seus traços mais característicos e determinantes.

Passada a temporada de veraneio, que se estende de dezembro a fevereiro, é cada vez mais difícil o retorno e readaptação das demandas cotidianas, sujeitando a população local a medidas condicionantes dessas atividades, mesmo que estas não tragam beneficio algum para os seus moradores.

Segundo Vieira (2001), há necessidade de um amplo conhecimento das culturas e dos ecossistemas, sobretudo em como as pessoas se relacionam com o ambiente e como elas enfrentam seus dilemas cotidianos; além do envolvimento dos cidadãos no planejamento das estratégias, pois eles são os maiores conhecedores da realidade local.

Isto posto, consideramos a importância para abrir mais frentes de estudo a respeito do turismo nos povoados Porto do Mato e Saco do Rio Real, concebendo que tudo isso pode nos conduzir a duas situações diferenciadas: uma diz respeito às experiências e aos significados que o turista elabora sobre o lugar visitado; a outra remete às indagações sobre as relações da comunidade receptora com o turismo. Até hoje as preocupações voltam-se ao atendimento dos interesses dos visitantes. Mas há grande carência em considerar o significado das interações que se processam, entre as informações oferecidas pelo ambiente e os significados apresentados pelos sujeitos envolvidos nesse processo. 


\section{Referencias Bibliográficas:}

ALMEIDA, Josimar Ribeiro de; BASTOS, A. C. Saramago (et al) Política e planejamento ambiental. Thex Ed. Rio De Janeiro, 2005.

BARROS. N. C. Croácia de. Manual de Geografia do Turismo: meio ambiente, cultura e paisagem. Recife. Universitária da UFPE. 1998.

BECKER, Olga M. S. Mobilidade espacial da população: conceitos, tipologia, contextos. In: CASTRO, Iná E. de; GOMES, Paulo C. da C. \& CORREA, Roberto L. (orgs.) Explorações geográficas. Rio de Janeiro: Bertrand Brasil, 1997. p.319-367.

CARLOS, Ana Fani Alessandri. O turismo e a produção do não-lugar. In: YAZIGI, Eduardo; CARLOS, Ana Fani Alessandri; CRUZ, Rita de Cassia Ariza da. (Orgs.). Turismo: espaço, paisagem e cultura. São Paulo: Hucitec, 1996. p. 25-37.

CASTRO, I. E. O espaço político local como condição de construção (mas também de negação) da democracia. In: Panorama da geografia brasileira. BORZACHIELLO, J. da S.; LIMA,L. C. ; ELIAS,D. (Org.). $1^{\text {a }}$ ed. São Paulo: ANNABLUME, 2006, v. 1, p. 49-63.

CASTRO, Josué de. Subdesenvolvimento: causa primeira de poluição. In.: CASTRO, Ana Maria de (org). Fome, um tema proibido. Últimos escritos de Josué de Castro. Petrópolis, vozes, 1983.

CORIOLANO, L. M. T. VASCONCELOS, F. P. Turismo e a relação sociedadenatureza - realidades, conflitos e resistências. Fortaleza: EdUECE, 2007.

CRUZ, Rita de C. A. da: As paisagens artificiais criadas pelo turismo - In: YAZIGI, C (org) Turismo e Paisagem - São Paulo: Contexto, 2002. 107-120.

DANTAS, EUTÓGIO W. C. Maritimidade nos Trópicos: por uma Geografia do Litoral. Fortaleza: Edições UFC, 2009.

DANTAS, E. W. C. "Litoralização" do Ceará: Fortaleza, da "capital do Sertão" a "Cidade do Sol". In: SILVA, J. B. da; DANTAS, E. Wanderley C; et al (org). Litoral e Sertão: natureza e sociedade no nordeste brasileiro. Fortaleza: Expressão gráfica. 2006. 446 p.

DINIZ, D.M.D.F.L. (org) Textos para História de Sergipe, Aracaju: UFS/BANESE. 1991.

GOMES, R C. S. A influência da ONG ASPED no processo de (re) organização espacial do povoado Porto do Mato, Estância, SE. São Cristóvão: Universidade Federal de Sergipe, 2006. 88 p. Monografia (monografia de bacharelado em Geografia) - Departamento de Geografia, Universidade Federal de Sergipe, São Cristóvão, 2006. 
GOMES, R.C.S. Uso e ocupação do solo da Praia do Saco Estância/SE: Percepção Ambiental dos Atores Sociais Locais a Cerca do Turismo e Veraneio. São Cristóvão: Universidade Federal de Sergipe, 2007. 38p. Monografia (monografia de especialização Lato Sensu)- Departamento de Biologia, Universidade Federal de Sergipe, São Cristóvão, 2007.

HAESBAERT, R. O Mito da Desterritorialização: do fim dos territórios a multiterritorialidades. 3 ed. Rio de Janeiro: Bertrand Brasil, 2007.

LEEB, Humberto. Porto do Mato: Santa Desobediência - O desafio da Fé. São Paulo: Fundação Banco do Brasil, 1996, p. 41.

LINHARES, Paulo. Cidade de água e sal. Por uma antropologia do litoral do nordeste sem cena e sem açúcar: Fundação Demócrito Rocha, 1992.

MORAES, Antônio Carlos Robert.Contribuições para a gestão da zonas costeira do Brasil. Elementos para uma geografia do litoral brasileiro.São Paulo, Hucitec, 1999.

RAFFESTIN, Claude. Por Uma Geografia do Poder. São Paulo: Editora Ática, 1993.

VIEIRA, P. F. Meio ambiente, desenvolvimento e planejamento. In: VIOLA, E. J (org).

Meio ambiente desenvolvimento e cidadania: Desafios para as ciências sociais:

Florianópolis Ed. UFSC, 2001 p. 45-97.

SEABRA, O. C. de Lima. A muralha que cerca o mar. Uma modalidade que cerca o uso do solo urbano. 1979. 122f. Dissertação (Dissertação de Mestrado em Geografia) Faculdade de Filosofia, Letras e Ciências Humanas. Universidade de São Paulo, São Paulo, 1979.

TULIK, O. Turismo e Meios de Hospedagem: Casas de Temporada. São Paulo: Roca, 2001.

WANDERLEY, LÍLIAN LINS. Litoral Sul de Sergipe: uma proposta de proteção ambiental e desenvolvimento sustentável. 1998. 247f. Tese (Tese de doutorado em Geografia)- Universidade Estadual Paulista Júlio de Mesquita Filho, Campus de Rio Claro, Rio Claro, 1998.

YÁZIGI, Eduardo. A alma do lugar: Turismo, planejamento e cotidiano em litorais e montanhas. São Paulo: Contexto, 2001. (Coleção Turismo Contexto)

Recebido para publicação em julho de 2009 Aprovado para publicação em dezembro de 2009 